\title{
habilidade Competitiva de Plantas de ArRoz com Biótipos de Capim-ARRoz Resistente ou Suscetível ao Quinclorac ${ }^{1}$
}

\author{
Competitive Ability of Rice Plants with Barnyardgrass Biotypes Resistant or Susceptible to \\ Quinclorac
}
TIRONI, S.P. ${ }^{2}$, GALON, L. ${ }^{3}$, CONCENÇO, G. ${ }^{4}$, FERREIRA, E.A. ${ }^{3}$, SILVA, A.F..$^{2}$, ASPIAZÚ, I. ${ }^{2}$, FERREIRA, F.A. ${ }^{5}$, SILVA, A.A. ${ }^{5}$ e NOLDIN, J.A. ${ }^{6}$

\begin{abstract}
RESUMO - Objetivou-se com este trabalho avaliar a habilidade competitiva de plantas de arroz cultivar BRS Pelota com biótipos de capim-arroz resistente ou suscetivel ao herbicida quinclorac. Para isso, foi instalado experimento em casa de vegetação, em delineamento completamente casualizado com quatro repetições, sendo os tratamentos dispostos em esquema fatorial $2 \times 6$. As unidades experimentais constaram de vasos plásticos contendo $10 \mathrm{dm}^{3}$ de solo, cujo $\mathrm{pH}$ e nivel de nutrientes foram previamente corrigidos. Os tratamentos consistiram na competição entre uma planta de arroz, cultivar BRS Pelota, com populações $(0,1,2,3,4$ ou 5 plantas por vaso) dos biótipos de capim-arroz resistente (ECH-13) ou suscetivel (ECH-12) ao herbicida quinclorac. As avaliações foram realizadas aos 40 dias após emergência, sendo avaliados; massa seca da parte aérea (MSPA), taxa de crescimento (TC), área foliar específica (AFE), razão de massa foliar (RMF), razão de área foliar (RAF) e índice de área foliar (IAF). A interferência no desenvolvimento do cultivar de arroz BRS Pelota foi proporcionalmente maior com o aumento da população de ambos os biótipos de capim-arroz. Os biótipos apresentaram, em geral, habilidade competitiva similar.
\end{abstract}

Palavras-chave: Echinochloa spp., Oryza sativa, interferência, índices relativos.

\begin{abstract}
The objective of this study was to evaluate the competitive ability of the rice cultivar $B R S$ Pelota with biotypes resistant or susceptible to the herbicide Quinclorac. The experiment was conducted under greenhouse conditions in a completely randomized design with four replications, with the treatments arranged in a $2 \times 6$ factorial. The experimental units consisted of plastic pots containing $10 \mathrm{dm}^{3}$ of soil, with $\mathrm{pH}$ and nutrient level being previously corrected. The treatments consisted of a competition between a rice plant, BRS Pelota cultivar, with populations (0, 1, 2, 3, 4 or 5 plants per pot) of the barnyardgrass biotypes resistant (ECH-13) or susceptible (ECH -12) to the herbicide Quinclorac. The evaluations were performed at $40 \mathrm{DAE}$, including shoot dry weight (MSPA), growth rate (TC), specific leaf area (SLA), leaf mass ratio (LWR), leaf area ratio (LAR) and leaf area index (LAI). The interference in the development of the BRS Pelota rice cultivar was proportionally higher with population increase of both barnyardgrass biotypes. The biotypes showed, in general, similar competitive ability.
\end{abstract}

Keywords: Echinochloa spp., Oryza sativa, interference, relative indices.

\section{INTRODUÇÃO}

Entre os fatores que limitam a produção de arroz irrigado, é expressiva a interferência causada pelas plantas daninhas, entre as quais se destaca o capim-arroz (Echinochloa spp.). As espécies pertencentes ao gênero Echinochloa apresentam elevada capacidade competitiva

Recebido para publicação em 7.7.2008 e na forma revisada em 5.6.2009.

2 Engo-Agr ${ }^{\circ}$, Doutorandos do Programa de Pós-Graduação, Departamento de Fitotecnia, Universidade Federal de Viçosa DFT/UFV, Bolsistas do CNPq, <siumar.tironi@gmail.com>; ${ }^{3}$ Eng - -Agr ${ }^{\circ}$, D.Sc. Pós-Doutorado, Bolsista PPJ/CNPq - DFT/UFV; ${ }^{4}$ Eng-o $-A g r{ }^{0}$, D.Sc., Valmont Irrigation, 7002 North $288^{\text {th }}$ Street, P.O. Box 358, Valley, Nebraska - 68064-0358, USA. ${ }^{5}$ Professor DFT/UFV, Bolsista do CNPq; ${ }^{6}$ Eng $^{-}$-Agr ${ }^{0}$, Ph.D., Pesquisador da área de Plantas Daninhas da EPAGRI/EEI, Itajaí-SC e Prof. colaborador do Programa de Pós-Graduação em Fitossanidade na Universidade Federal de Pelotas - UFPel. 
mesmo em baixas populações; em alguns casos, as medidas de controle que eliminem até $99 \%$ da infestação podem não ser suficientes para evitar perdas de produtividade que justifiquem a adoção de medidas de controle (Galon et al., 2007a,b; Agostinetto et al., 2007). Os autores relatam ainda que o capim-arroz ocorre em altos niveis de infestação, distribuição e semelhanças morfofisiológicas com a cultura, sendo esta última característica a que mais dificulta a adoção de controle com o uso de herbicidas.

No arroz irrigado, a competição por água geralmente é pouco expressiva, pelo fato de que 30 dias após a emergência da cultura a lâmina de água é estabelecida (Gibson et al., 2001). A principal forma de interferência que se estabelece entre capim-arroz e arroz irrigado é a competição pelos recursos luz, nutrientes, $\mathrm{CO}_{2}$ e espaço, constituindo-se nos principais fatores limitantes da produtividade nas lavouras de arroz irrigado nos Estados do Rio Grande do Sul e de Santa Catarina.

Alguns fatores podem determinar maior competitividade das plantas daninhas sobre as espécies cultivadas, destacando-se o porte e a arquitetura; a velocidade de germinação e estabelecimento da plântula; a velocidade do crescimento e extensão do sistema de raízes; a suscetibilidade às intempéries climáticas, como veranicos e geadas; e a capacidade de produção e liberação de substâncias químicas com propriedades alelopáticas (Bitencourt et al., 2007; Rizzardi et al., 2008). Destacam-se também algumas espécies daninhas que podem alocar maior quantidade de assimilados às folhas; assim, elas desenvolvem maior área foliar e, consequentemente, maior interceptação luminosa e taxa fotossintética, aumentando a capacidade competitiva (Larcher, 2006). O capim-arroz, por ser espécie de metabolismo $\mathrm{C}_{4}$, possui maior eficiência fotossintética quando comparado com a cultura do arroz $\left(\mathrm{C}_{3}\right)$, com rápido crescimento (Kissmann, 1997).

Pesquisas envolvendo a capacidade competitiva de culturas versus plantas daninhas permitem desenvolver estratégias de manejo, já que podem definir caracteristicas que confiram maior habilidade competitiva às espécies cultivadas em detrimento das infestantes (Fleck et al., 2006; Agostinetto et al., 2007;
Galon et al., 2007a, b). A habilidade competitiva caracteriza-se pela dominância de um indivíduo sobre seus vizinhos, os quais utilizam, simultaneamente, um mesmo recurso com limitada disponibilidade no meio (Aarssen, 1983). A habilidade competitiva pode ser estudada, quanto aos efeitos, sob os aspectos de supressão do crescimento de vizinhos e tolerância à presença destes (Goldberg \& Landa, 1991). Nos agroecossistemas, o efeito supressivo deve preponderar em relação à tolerância das culturas, por reduzir a massa seca e a produção de sementes das plantas daninhas e beneficiar seu manejo nas culturas subsequentes (Jordan, 1993).

O principal método de controle de plantas daninhas em arroz irrigado é o químico, em razão da eficiência, praticidade e economia com mão-de-obra (Erasmo et al., 2004). Contudo, o uso contínuo de herbicidas de mesmo mecanismo de ação, na mesma área, aumenta a pressão de seleção de biótipos resistentes e dificulta o controle pelo método químico. Exemplo disso é o surgimento da resistência de biótipos de capim-arroz a vários mecanismos de ação em todo o mundo (Ruiz-Santella et al., 2003). No Brasil, destaca-se a resistência de capim-arroz ao quinclorac, que está amplamente distribuída nas lavouras orizícolas do Sul do País, região de maior participação na produção nacional do cereal (Andres et al., 2007; Concenço et al., 2008a).

Biótipos de capim-arroz resistentes e suscetiveis ao quinclorac, quando em alta população, apresentam habilidade competitiva similar, porém em baixa intensidade de competição os biótipos suscetíveis apresentaram maior potencial competitivo (Concenço et al., 2008; Schuch et al., 2008). No entanto, estudos preliminares indicam que os biótipos resistentes apresentam ampla variação morfofisiológica entre si e que, provavelmente, a resistência se desenvolveu independentemente nas regiões produtoras de arroz (Andres et al., 2007), podendo haver distintas características entre essas populações.

O herbicida quinclorac é classificado como mimetizador de auxinas; seu uso no Brasil iniciou-se em 1990, sendo registrado para a cultura do arroz, visando o controle de Echinochloa crusgalli, E. cruspavonis, E. colona, 
Aeschynomene denticulata e A. rudis (ANVISA, 2008). Esse herbicida foi intensamente utilizado durante a década de 1990, quando surgiram os primeiros casos de biótipos de capim-arroz resistentes (Concenço et al., 2008a, b).

Com o surgimento de mutações naturais, as plantas podem alterar várias características fisiológicas com importância agronômica, como os biótipos de azevém (Lolium multiflorum) resistentes ao herbicida glyphosate, que apresentam menor habilidade competitiva quando comparados aos biótipos suscetiveis e tendem a desaparecer na ausência do agente selecionador - neste caso, o herbicida glyphosate (Ferreira et al., 2008).

Objetivou-se com este trabalho avaliar a habilidade competitiva de plantas de arroz da variedade BRS Pelota com biótipos de capimarroz resistente ou suscetivel ao herbicida quinclorac.

\section{MATERIAL E MÉTODOS}

Foi conduzido experimento em ambiente protegido (casa de vegetação) com temperatura variável entre 22 e $27^{\circ} \mathrm{C}$ e iluminação natural. As unidades experimentais constaram de vasos plásticos com $10 \mathrm{dm}^{3}$ de solo, previamente corrigido e adubado de acordo com análise de solo. O delineamento experimental utilizado foi o completamente casualizado com quatro repetições, sendo os tratamentos dispostos em esquema fatorial $2 \times 6$.

O fator A foi composto pelos biótipos de capim-arroz resistente (ECH-13) suscetivel (ECH-12) ao quinclorac, já o B constou da competição entre uma planta de arroz do cultivar BRS Pelota no centro da unidade experimental e populações $(0,1,2,3,4$ ou 5 plantas por vaso) dos dois biótipos de capim-arroz coletados em lavouras arrozeiras no município de Itajaí-SC e gentilmente cedidos pelo pesquisador José Aberto Noldin, da Epagri/EEI, Itajai/SC, para que fosse possivel a realização deste trabalho. Foram semeadas três sementes de arroz no centro de cada unidade experimental, e na periferia dez sementes dos biótipos de capimarroz resistente ou suscetivel ao herbicida quinclorac, de acordo com o tratamento proposto.
Dez dias após a emergência (DAE) das plântulas efetuou-se o desbaste, deixando-se uma planta de arroz no centro de cada unidade experimental e $0,1,2,3,4$ ou 5 plantas por vaso do biótipo de capim-arroz, conforme o tratamento.

As avaliações foram realizadas aos $40 \mathrm{DAE}$, sendo as plantas de arroz seccionadas rente ao solo, separando-se a parte aérea do sistema de raízes. As raízes foram lavadas em água corrente, e a parte aérea foi separada em colmos e folhas. As raízes foram acondicionadas em sacos de papel e levadas à estufa com circulação forçada de ar, à temperatura de $60^{\circ} \mathrm{C}$ até massa constante, para determinação da massa seca de raízes (MR). A parte aérea das plantas foi acondicionada em sacos plásticos contendo algodão embebido em água e colocada em caixa de poliestireno expandido (Isopor ${ }^{\circledR}$ ) com gelo, evitando a desidratação. Imediatamente após a coleta, as plantas foram levadas a laboratório, onde se separaram as folhas dos colmos, e em seguida realizou-se a aferição da área foliar (AF), em determinador eletrônico. Os colmos e folhas foram acondicionados separadamente em sacos de papel e levados à estufa de circulação forçada de ar a $60{ }^{\circ} \mathrm{C}$ até massa constante, para obtenção da massa seca das folhas (MF) e massa seca dos colmos (MC). Com a soma dessas massas, obteve-se a massa seca da parte aérea (MSPA). Somando-se MSPA + MR, determinou-se a massa seca total (MST).

Com os valores das variáveis diretas foram calculados os indices taxa de crescimento (TC), área foliar específica (AFE), razão de massa foliar (RMF), razão de área foliar (RAF) e índice de área foliar (IAF), sendo as seguintes equações utilizadas para a determinação dessas variáveis:

$$
\begin{array}{ll}
\mathrm{TC}=\mathrm{MST} / \mathrm{t} & \left(\mathrm{g} \mathrm{dia}^{-1}\right) \\
\mathrm{AFE}=\mathrm{AF} / \mathrm{MF} & \left(\mathrm{m}^{2} \mathrm{~g}^{-1}\right) \\
\mathrm{RMF}=\mathrm{MF} / \mathrm{MST} & \left(\mathrm{g} \mathrm{g}^{-1}\right) \\
\mathrm{RAF}=\mathrm{AF} / \mathrm{MST} & \left(\mathrm{m}^{2} \mathrm{~g}^{-1}\right) \\
\mathrm{IAF}=\mathrm{AF} / \mathrm{P} & \left(\mathrm{m}^{2} \mathrm{~m}^{-2}\right)
\end{array}
$$

em que $\mathrm{t}=$ período em dias, desde a emergência até a colheita das plantas; e $\mathrm{P}=$ área da superfície do terreno.

Planta Daninha, Viçosa-MG, v. 27, n. 2, p. 257-263, 2009 
Os dados obtidos foram verificados quanto à normalidade e homogeneidade e submetidos à análise de variância pelo teste $\mathrm{F}$. Em caso de significância, aplicou-se o teste de Duncan para avaliar o efeito do aumento da densidade de plantas de capim-arroz sobre o cultivar de arroz BRS Pelota, bem como o teste da Diferença Mínima Significativa (DMS), para avaliar as diferenças entre biótipos resistente e suscetivel em cada densidade de competição. Todas as análises foram realizadas a $5 \%$ de probabilidade.

\section{RESULTADOS E DISCUSSÃO}

Observou-se redução da variável massa seca da parte aérea (MSPA) do arroz conforme a população de ambos os biótipos foi aumentada (Tabela 1). Não houve diferença na MSPA das plantas de arroz cultivadas na ausência ou com até uma planta de capim-arroz. Considerando que a MSPA das plantas de arroz que competiram com biótipos suscetiveis mostrou fragmentação dos resultados em dois niveis após a competição de 1:(1), para o biótipo resistente os resultados não diferiram após essa proporção de plantas. Esses resultados estão de acordo com os encontrados por Galon et al. (2007a), ao relatarem que, quando ocorre acréscimo da população de plantas de

Tabela 1 - Massa seca de parte aérea (MSPA) de plantas de arroz irrigado, cv. BRS Pelota, em função da competição com plantas de capim-arroz dos biótipos resistente ou suscetível ao quinclorac

\begin{tabular}{|c|c|c|c|c|}
\hline \multicolumn{2}{|c|}{ Plantas em competição } & \multicolumn{2}{|c|}{ MSPA (g por planta) } & \multirow{2}{*}{ Diferença $^{\underline{2}}$} \\
\hline Arroz & Capim-arroz & Resistente $^{\underline{1}}$ & Suscetível $^{1 /}$ & \\
\hline 1 & 0 & $0,69 \mathrm{a}^{\frac{3}{}}$ & $0,89 \mathrm{a}$ & $-0,20^{\mathrm{ns}}$ \\
\hline 1 & 1 & $0,79 \mathrm{a}$ & $1,08 \mathrm{a}$ & $-0,29$ \\
\hline 1 & 2 & $0,25 \mathrm{~b}$ & $0,62 \mathrm{~b}$ & $-0,38$ \\
\hline 1 & 3 & $0,27 \mathrm{~b}$ & $0,30 \mathrm{bc}$ & $-0,03$ \\
\hline 1 & 4 & $0,22 \mathrm{~b}$ & $0,25 \mathrm{bc}$ & $-0,03$ \\
\hline 1 & 5 & $0,17 \mathrm{~b}$ & $0,16 \mathrm{c}$ & $+0,01$ \\
\hline
\end{tabular}

1/ Refere-se ao biótipo de capim-arroz com o qual a planta de arroz irrigado avaliada competia. ${ }^{2 / \text { ns }}$ não significativo; $* * *$ significativo a 5 e $1 \%$ de probabilidade de erro, respectivamente, pelo teste da DMS. ${ }^{3 /}$ Médias seguidas da mesma letra, na coluna, não diferem pelo teste de Duncan a $5 \%$ de probabilidade. capim-arroz competindo com diferentes variedades de arroz irrigado, há perda de produtividade de grãos de arroz.

Houve redução na taxa de crescimento (TC) com o aumento do nivel de competição com capim-arroz, tanto para biótipos resistentes como para suscetiveis (Tabela 2). Todavia, não se observou diferença quando a planta de arroz esteve em competição com apenas uma planta de capim-arroz resistente, sendo idêntica ao tratamento em que a planta se desenvolveu livre de competição. Para o biótipo suscetivel, quando a cultura competiu com apenas uma planta, maior TC foi observada, diferindo da testemunha sem competição. A TC do arroz se manteve estável nas competições acima de duas plantas de capim-arroz do biótipo resistente, enquanto para o suscetivel houve diferença entre as três menores populações de plantas daninhas $(0,1$ e 2$)$ - tratamentos estes que diferiram dos demais. A TC da cultura do foi maior quando em competição com o biótipo suscetivel, quando comparado com o resistente ao quinclorac, nas três menores populações estudadas. Deve-se ressaltar que, quando não se denotam diferenças entre espécies ou biótipos que competem entre si, significa que não há efeito de um sobre outro, ou que a habilidade competitiva dessas plantas em interferir uma sobre a outra se equivale, ou,

Tabela 2 - Taxa de crescimento absoluto (TC) de plantas de arroz irrigado, cv. BRS Pelota, em função da competição com plantas de capim-arroz dos biótipos resistente ou suscetível ao quinclorac

\begin{tabular}{|c|c|c|c|c|}
\hline \multicolumn{2}{|c|}{ Plantas em competição } & Resistente $^{\underline{1}}$ & Suscetível $^{1-}$ & Diferença ${ }^{2}$ \\
\hline Arroz & Capim-arroz & \multicolumn{3}{|c|}{ TC (g por dia) } \\
\hline 1 & 0 & $0,015 \mathrm{a}^{3 /}$ & $0,022 \mathrm{~b}$ & $-0,007 *$ \\
\hline 1 & 1 & $0,017 \mathrm{a}$ & $0,044 \mathrm{a}$ & $-0,027 * *$ \\
\hline 1 & 2 & $0,005 \mathrm{~b}$ & $0,014 \mathrm{c}$ & $-0,009 *$ \\
\hline 1 & 3 & $0,006 \mathrm{~b}$ & $0,006 \mathrm{~d}$ & $0,000^{\text {ns }}$ \\
\hline 1 & 4 & $0,004 \mathrm{~b}$ & $0,005 \mathrm{~d}$ & $-0,0011^{\mathrm{ns}}$ \\
\hline 1 & 5 & $0,003 \mathrm{~b}$ & $0,003 \mathrm{~d}$ & $0,000^{\text {ns }}$ \\
\hline
\end{tabular}

1/ Refere-se ao biótipo de capim-arroz com o qual a planta de arroz irrigado avaliada competia. ${ }^{2 / \text { ns }}$ não significativo; $* * *$ significativo a 5 e $1 \%$ de probabilidade de erro, respectivamente, pelo teste da DMS. ${ }^{3 /}$ Médias seguidas da mesma letra, na coluna, não diferem pelo teste de Duncan a $5 \%$ de probabilidade. 
ainda, que as plantas possuem habilidades competitivas basicamente semelhantes para a variável em estudo (Agostinhetto et al., 2008; Fleck et al., 2008).

A área foliar específica (AFE) do arroz, cultivar BRS Pelota, não foi influenciada pelo aumento da densidade de plantas de capimarroz dos biótipos resistente ou suscetivel ao quinclorac (Tabela 3). A AFE descreve indiretamente a adaptação da planta à quantidade e qualidade da luz do ambiente no qual está estabelecida, ou seja, valores mais altos representam folhas menos espessas, em razão da deficiência na quantidade de luz recebida pela planta. Sob condições de deficiência luminosa, a planta tende a incrementar sua área foliar para maximizar a captação da radiação, sem correspondente aumento na massa seca dessa folha; como consequência, a folha fica menos espessa. Por outro lado, sob luz excessiva, as plantas tendem a diminuir a área foliar, como forma de proteger os cloroplastos do excesso de luz, mantendo a massa seca da folha; em decorrência disso, a folha apresenta menor AFE, sendo mais espessa que folhas que se desenvolveram sob nivel adequado de radiação solar (Larcher, 2006).

Houve moderada redução na razão de massa foliar (RMF) das plantas de arroz com o aumento da competição com os biótipos de capim-arroz (Tabela 4). Sob influência do biótipo resistente somente foram observadas diferenças nas duas maiores densidades de competição (1:4) e (1:5), em relação aos demais tratamentos; no entanto, a RMF das plantas de arroz sob influência do biótipo suscetivel somente diferiu na maior população. Na comparação entre biótipos, os dois primeiros tratamentos demonstraram significância, e o capim-arroz resistente causou menor interferência sob o cultivar BRS Pelota. A RMF indica a porcentagem de massa seca acumulada em folhas em relação à massa seca total acumulada na parte aérea da planta. Assim, menores valores desta variável podem indicar que a planta está sob alta competição e privilegia o acúmulo de massa em colmos, como forma de incrementar sua estatura e sobressair a competição por luz. Da mesma forma, maiores valores desta variável indicam que a planta recebe luz adequadamente e privilegia o acúmulo de massa proporcional ao aumento da área foliar em detrimento dos colmos (Larcher, 2006).

A razão de área foliar ( $R A F)$ do arroz sofreu interferência negativa com o aumento das populações de capim-arroz em competição, para ambos os biótipos (Tabela 5). A RAF do arroz, quando em competição com qualquer população estudada de capim-arroz resistente,

Tabela 3 - Área foliar específica (AFE) de plantas de arroz irrigado, cv. BRS Pelota, em função da competição com plantas de capim-arroz dos biótipos resistente ou suscetível ao quinclorac

\begin{tabular}{|c|c|c|c|c|}
\hline \multicolumn{2}{|c|}{ Plantas em competição } & Resistente $^{\frac{1}{}}$ & Suscetível $^{1 /}$ & Diferença $^{{ }^{2}}$ \\
\hline Arroz & Capim-arroz & \multicolumn{3}{|c|}{ AFE $\left(\mathrm{m}^{2} \mathrm{~g}^{-1}\right)$} \\
\hline 1 & 0 & $360,0 \mathrm{a}^{\frac{3}{}}$ & $272,5 \mathrm{a}$ & $+87,5^{\text {ns }}$ \\
\hline 1 & 1 & $256,7 \mathrm{a}$ & $233,1 \mathrm{a}$ & $+23,6^{\text {ns }}$ \\
\hline 1 & 2 & $319,2 \mathrm{a}$ & $206,3 \mathrm{a}$ & $+112,9^{\text {ns }}$ \\
\hline 1 & 3 & $364,6 \mathrm{a}$ & $246,9 \mathrm{a}$ & $+117,7^{\text {ns }}$ \\
\hline 1 & 4 & $331,7 \mathrm{a}$ & $263,9 \mathrm{a}$ & $+67,8^{\mathrm{ns}}$ \\
\hline 1 & 5 & $335,9 \mathrm{a}$ & $277,5 \mathrm{a}$ & $+58,4^{\mathrm{ns}}$ \\
\hline
\end{tabular}

${ }^{1 /}$ Refere-se ao biótipo de capim-arroz com o qual a planta de arroz irrigado avaliada competia. ${ }^{2 / \text { ns }}$ não significativo; *,** significativo a 5 e $1 \%$ de probabilidade de erro, respectivamente, pelo teste da DMS. ${ }^{3 /}$ Médias seguidas da mesma letra, na coluna, não diferem pelo teste de Duncan a $5 \%$ de probabilidade.

Tabela 4 - Razão de massa foliar (RMF) de plantas de arroz irrigado, cv. BRS Pelota, em função da competição com plantas de capim-arroz dos biótipos resistente ou suscetível ao quinclorac

\begin{tabular}{|c|c|c|c|c|}
\hline \multicolumn{2}{|c|}{ Plantas em competição } & Resistente $^{1 /}$ & Suscetível $^{1 /}$ & Diferença $^{2}{ }^{-1}$ \\
\hline Arroz & Capim-arroz & \multicolumn{3}{|c|}{${\text { RMF }\left(\mathrm{g} \mathrm{g}^{-1}\right)}$} \\
\hline 1 & 0 & $0,62 \mathrm{a}^{\frac{3}{}}$ & $0,59 \mathrm{a}$ & $+0,03^{*}$ \\
\hline 1 & 1 & $0,60 \mathrm{a}$ & $0,56 \mathrm{ab}$ & $+0,04^{*}$ \\
\hline 1 & 2 & $0,57 \mathrm{ab}$ & $0,56 \mathrm{ab}$ & $+0,01^{\text {ns }}$ \\
\hline 1 & 3 & $0,58 \mathrm{ab}$ & $0,56 \mathrm{ab}$ & $+0,02^{\text {ns }}$ \\
\hline 1 & 4 & $0,55 \mathrm{~b}$ & $0,55 \mathrm{ab}$ & $0,00^{\text {ns }}$ \\
\hline 1 & 5 & $0,56 \mathrm{~b}$ & $0,54 \mathrm{~b}$ & $+0,02^{\text {ns }}$ \\
\hline
\end{tabular}

${ }^{1 /}$ Refere-se ao biótipo de capim-arroz com o qual a planta de arroz irrigado avaliada competia. ${ }^{2 /}$ ns não significativo; *,** significativo a 5 e $1 \%$ de probabilidade de erro, respectivamente, pelo teste da DMS. ${ }^{3 /}$ Médias seguidas da mesma letra, na coluna, não diferem pelo teste de Duncan a $5 \%$ de probabilidade. 
diferiu do tratamento com ausência de competição. Já nos tratamentos com plantas suscetiveis, quando o arroz competiu com apenas uma planta, não houve diferença da testemunha livre de competição. Quando a influência dos biótipos foi comparada sob o mesmo nivel de competição, observou-se diferença em todos os tratamentos, com exceção da maior intensidade de competição. Em razão do comportamento desta variável, ou seja, redução do valor do RAF em função do aumento da densidade de competição, pode-se inferir que provavelmente a massa seca total da parte aérea diminuiu com o aumento da competição, enquanto a aérea foliar de plantas se manteve estáve1, o que acarretou menor valor desta variável mesmo sem alteração da área foliar da planta. No entanto, uma hipótese é de que a espessura da folha nessa situação pode ter sido alterada em função da intensidade de competição à qual a planta estava submetida (Silva et al., 2005).

O indice de área foliar (IAF) do arroz sofreu influência quando em competição com o capim-arroz suscetivel e resistente ao quinclorac (Tabela 6). Na competição com o biótipo resistente, os três primeiros tratamentos não diferiram; contudo, para o biótipo suscetível, todos os tratamentos com a presença da planta daninha diferiram da testemunha, com aumento da densidade de população de capim-arroz. Na comparação entre os biótipos,

Tabela 5 - Razão de área foliar (RAF) de plantas de arroz irrigado cv. BRS Pelota, em função da competição com plantas de capim-arroz dos biótipos resistente ou suscetível ao quinclorac

\begin{tabular}{|c|c|c|c|c|}
\hline \multicolumn{2}{|c|}{ Plantas em competição } & Resistente $^{\underline{1}}$ & Suscetível $^{1 /}$ & Diferença $^{2 /}$ \\
\hline Arroz & Capim-arroz & \multicolumn{3}{|c|}{ RAF $\left(\mathrm{m}^{2} \mathrm{~g}^{-1}\right)$} \\
\hline 1 & 0 & $248,3 \mathrm{a}^{\frac{3}{}}$ & $165,4 \mathrm{a}$ & $+82,9^{* *}$ \\
\hline 1 & 1 & $207,4 \mathrm{~b}$ & $169,5 \mathrm{a}$ & $+37,9^{*}$ \\
\hline 1 & 2 & $204,3 \mathrm{~b}$ & $138,8 \mathrm{~b}$ & $+65,5^{* *}$ \\
\hline 1 & 3 & $195,2 \mathrm{bc}$ & $142,6 \mathrm{~b}$ & $+52,6^{*}$ \\
\hline 1 & 4 & $177,5 \mathrm{c}$ & $117,8 \mathrm{c}$ & $+59,7^{*}$ \\
\hline 1 & 5 & $144,9 \mathrm{~d}$ & $116,1 \mathrm{c}$ & $+28,8^{\mathrm{ns}}$ \\
\hline
\end{tabular}

1/ Refere-se ao biótipo de capim-arroz com o qual a planta de arroz irrigado avaliada competia. $\stackrel{2 / \text { ns }}{ }$ não significativo; *,** significativo a 5 e $1 \%$ de probabilidade de erro, respectivamente, pelo teste da DMS. ${ }^{3 /}$ Médias seguidas da mesma letra, na coluna, não diferem pelo teste de Duncan a $5 \%$ de probabilidade. observou-se diferença na interferência sobre a cultura quando competindo apenas com uma planta [1:(1)] de capim-arroz, e o biótipo suscetível apresentou maior interferência. Em algumas situações, quando existe espaço disponivel, o biótipo de capimarroz suscetivel pode ser mais competitivo que o resistente contra o cultivar de arroz BRS Pelota. Resultados semelhantes foram observados em outros trabalhos onde a competição entre biótipos de plantas daninhas suscetiveis e resistentes com espécies cultivadas foi avaliada; o biótipo resistente obteve certa vantagem na competição pelos recursos do meio, em relação ao suscetivel (Concenço et al., 2008a; Ferreira et al., 2008).

A interferência no crescimento do cultivar de arroz BRS Pelota foi proporcionalmente maior com a elevação da população de capimarroz de ambos os biótipos - resistente ou suscetivel ao quinclorac. Quando se compararam os biótipos na mesma intensidade de competição, observou-se que a habilidade competitiva é bastante similar, não havendo, em geral, alterações nas características morfofisiológicas das plantas de arroz em função dos indices estudados. No entanto, para algumas variáveis, o biótipo suscetível apresentou maior interferência sobre o arroz, principalmente quando sob baixa densidade de plantas na área.

Tabela 6 - Índice de área foliar (IAF) de plantas de arroz irrigado, cv. BRS Pelota, em função da competição com plantas de capim-arroz dos biótipos resistente ou suscetível ao quinclorac

\begin{tabular}{|c|c|c|c|c|}
\hline \multicolumn{2}{|c|}{ Plantas em competição } & Resistente $^{\underline{1}}$ & Suscetível $^{1 /}$ & Diferença $^{2 /}$ \\
\hline Arroz & Capim-arroz & \multicolumn{3}{|c|}{ IAF $\left(\mathrm{m}^{2} \mathrm{~m}^{-2}\right)$} \\
\hline 1 & 0 & $0,26 \mathrm{a}^{\mathrm{3}^{-}}$ & $0,30 \mathrm{a}$ & $-0,04^{\mathrm{ns}}$ \\
\hline 1 & 1 & $0,24 \mathrm{a}$ & $0,18 \mathrm{~b}$ & $+0,06^{*}$ \\
\hline 1 & 2 & $0,19 \mathrm{ab}$ & $0,20 \mathrm{~b}$ & $-0,01^{\mathrm{ns}}$ \\
\hline 1 & 3 & $0,14 \mathrm{~b}$ & $0,15 \mathrm{~b}$ & $-0,01^{\mathrm{ns}}$ \\
\hline 1 & 4 & $0,14 \mathrm{~b}$ & $0,18 \mathrm{~b}$ & $-0,04^{\mathrm{ns}}$ \\
\hline 1 & 5 & $0,15 \mathrm{~b}$ & $0,19 \mathrm{~b}$ & $-0,04^{\mathrm{ns}}$ \\
\hline
\end{tabular}

1/ Refere-se ao biótipo de capim-arroz com o qual a planta de arroz

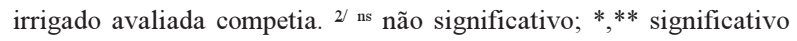
a 5 e $1 \%$ de probabilidade de erro, respectivamente, pelo teste da DMS. ${ }^{3 /}$ Médias seguidas da mesma letra, na coluna, não diferem pelo teste de Duncan a $5 \%$ de probabilidade. 


\section{AGRADECIMENTOS}

Ao Conselho Nacional de Desenvolvimento Científico e Tecnológico (CNPq), pelas concessões de bolsas; e ao pesquisador da EPAGRIItajaí/SC, área de Plantas Daninhas, e professor colaborador do Programa de Pós-Graduação em Fitossanidade, área do Conhecimento em Plantas Daninhas, da Universidade Federal de Pelotas, Ph.D. José Alberto Noldin, por ceder gentilmente as sementes de populações de biótipos de capim-arroz resistente e suscetível ao herbicida quinclorac, coletadas em lavouras arrozeiras no município de Itajaí-SC este pesquisador foi o determinador da resistência dessa espécie daninha estudada neste experimento.

\section{LITERATURA CITADA}

AARSSEN, L. W. Ecological combining ability and competitive combining ability in plants: toward a general evolutionary theory of coexistence in systems of competition. Am. Natur., v. 122, n. 6, p. 707-731, 1983

AGOSTINETTO, D. et al. Competitividade relativa entre cultivares de arroz irrigado e biótipos de capim-arroz (Echinochloa spp.). Planta Daninha, v. 26, n. 4, p. 757-766, 2008.

AGOSTINETTO, D. et al. Interferência de capim-arroz (Echinochloa spp.) na cultura do arroz irrigado (Oryza sativa) em função da época de irrigação. Planta Daninha, v. 25, n. 4, p. 689-696, 2007.

ANDRES, A. et al. Detecção da resistência de capim-arroz (Echinochloa sp.) ao herbicida quinclorac em regiões orizícolas do sul do Brasil. Planta Daninha, v. 25, n. 1, p. 221-226, 2007.

ANVISA. Relatório do Agrotóxico-Facet DF. Disponível $\mathrm{em}:<\mathrm{http}: / /$ www4 anvisa.gov.br $>$. Acesso em: 3 de Abril de 2008.

BITENCOURT, H. R.; SANTOS, L. S.; SOUZA FILHO, A P. S. Atividade alelopática de chalcona sintética de seus precursores e de cetonas e aldeídos relacionados. Planta Daninha, v. 25, n. 4, p. 747-753, 2007.

CONCENÇO, G. et al. Competitividade de biótipos de capim-arroz resistente e suscetível ao quinclorac. Planta Daninha, v. 26, n. 1, p. 195-202, 2008

CONCENÇO, G. et al. Método rápido para detecção de resistência de capim-arroz (Echinochloa spp.) ao quinclorac. Planta Daninha, v. 26, n. 2, p. 429-437, 2008.
ERASMO, E. A. L.; PINHEIRO, L. L. A.; COSTA, N. V. Levantamento fitossociológico das comunidades de plantas infestantes em áreas de produção de arroz irrigado cultivado sob diferentes sistemas de manejo. Planta Daninha, v. 22, n. 2, p. 195-201, 2004.

FLECK, N. G. et al. Interferência de Raphanus sativus sobre cultivares de soja durante a fase vegetativa de desenvolvimento da cultura. Planta Daninha, v. 24, n. 3, p. 425-434, 2006.

FLECK, N. G. et al. Competitividade relativa entre cultivares de arroz irrigado e biótipo de arroz-vermelho. Planta Daninha, v. 26, n. 1, p. 101-111, 2008.

FERREIRA, E. A. et al. Potencial competitivo de biótipos de azevém (Lolium multiflorum). Planta Daninha, v. 26, n. 2, p. 261-269, 2008.

GALON, L. et al. Estimativa das perdas de produtividade de grãos em cultivares de arroz (Oryza sativa) pela interferência do capim-arroz (Echinochloa spp.). Planta Daninha, v. 25, n. 3 , p. $697-707,2007 \mathrm{a}$

GALON, L. et al. Níveis de dano econômico para decisão de controle de capim-arroz (Echinochloa spp.) em arroz irrigado (Oryza sativa). Planta Daninha, v. 25, n. 4, p. 709-718, $2007 \mathrm{~b}$

GIBSON, K. D. et al. Water-seeded rice cultivars differ in ability to interfere with watergrass. Agron. J., v. 93, n. 3, p. 326-332, 2001.

GOLDBERG, D. E.; LANDA, K. Competitive effect and response: hierarchies and correlated traits in the early stages of competition. J. Ecol., v. 79, n. 4, p. 1013-1030, 1991.

JORDAN, N. Prospects for weed control through crop interference. Ecol. Appl., v. 3, n. 1, p. 84-91, 1993.

KISSMANN, K. G. Plantas infestantes e nocivas. 2.ed. São Paulo: BASF, 1997. Tomo I. 825 p.

LARCHER, W. Ecofisiologia vegetal. São Carlos: RIMA, 2006. $636 \mathrm{p}$.

RIZZARDI, A. et al. Potencial alelopático de extratos aquosos de genótipos de canola sobre Bidens pilosa. Planta Daninha, v. 26, n. 4, p. 717-724, 2008.

RUIZ-SANTELLA, J. P.; FISCHER, A. J.; DePRADO, R. Alternative control of two biotypes of Echinochloa phyllopogon susceptible and resistant to fenoxaprop-ethyl. Comm. Agric. Appl. Biol. Sci., v. 68, n. 4, p. 403-407, 2003

SCHUCH, L. O. B. et al. Comprimento de raízes de biótipos de capim-arroz resistente e suscetível ao quinclorac em competição. Planta Daninha, v. 26, n. 4, p. 893-900, 2008.

SILVA, A. C. et al. Análise de crescimento de Brachiaria brizantha submetida a doses reduzidas de fluazifop-p-butil. Planta Daninha, v. 23, n. 1, p. 45-51, 2005. 